\title{
Vaccine hesitancy and refusal: why the Italian clinical microbiologists must get up and start acting
}

Dear Readers,

The wide diffusion of the behavioral phenomenon related to the disrepute of vaccines is not new: this dislike toward vaccination just started with the availability of the very first vaccine made from cowpox preparation by Edward Jenner in the late 1700s.

At that time, only some clergymen protested about the unnatural use of animal derived material in humans, and some parents were afraid by the invasiveness of the procedure (2).

Nowadays, the fact is assuming a large and unbelievable global dimension: Googling for vaccine hesitancy and for vaccine refusal finds 387.000 (in 0.22 seconds) and 471.000 (in 0.39 seconds) results, respectively (Accessed on the World Wide Web on June $4^{\text {th }}, 2016$ at $4.30 \mathrm{pm}$ CET).

Several different factors have been found to contribute to this phenomenon: first of all the current tendency to make shortcuts along the path to estimate risk, thus achieving quick but highly doubtful conclusions, basically comparable with empirical decisions, educated guess or common sense. All of this way to decide are frequently useful in all day life, but are really far away from a science-based conclusion.

Other factors have been reported to enhance the vaccine hesitancy, such as: the success of vaccination (the reduced number of cases obtained just thanks the wide use and efficacy of vaccines makes the perception of the risk quite weak... this disease is no more around!), the unnaturalness of vaccination (including the hypothetical risk of adjuvants: this is a common idea among people that follows a natural way of life) and, last but not least, a huge loss in public confidence in vaccination (3).

This is becoming particularly relevant when against vaccines opinions are made public through the most diffuse social media. The problem is even more acute when public figures, such as famous TV and movie stars or DJs get up during a television show and not only express their personal beliefs about vaccination (mainly based on not scientifically documentable certainties about vaccines and vaccination practices! .... scientific background related) but they also provide the audience with unreliable data on risks and mortality rates vaccinerelated. This just happened recently during the Italian Public Television show named (was this just by chance?) Virus.

In this specific case, the disinformation process was even made worst due to the absence of expert scientists with the opportunity to contradict these dangerous and false ideas!

The possibility to publicly express personal (not evidence supported) opinions on topics that are so far from a person expertise is likely more dangerous than broadcast the results of many poorly designed studies that correlated vaccines and autism conducted in a recent past (1). This uncorrected information provided by famous people belonging to the show business directly to a large audience is given without any requirement for divulgation efforts, always requested when true scientific data are made available to common people.

Considering the too many episodes of misinformation about vaccines, we feel as a mandatory ethical duty for all the Clinical Microbiologists to get up and start to loudly proclaim, even in their routine professional activity, the fundamental relevance of vaccines in saving lives and improving the health of billions of humans. This could be done in different ways, such as providing timely adjourned evidence-based scientific information about vaccine schedule and proof of efficacy and safety to anyone, but also by using the same storytelling strategies commonly in place by the anti-vaccine movement (4).

\section{References}

1. Gerber JS, Offit PA. Vaccines and autism: a tale of shifting hypotheses. Clin Infect Dis 2009;48:456-61.

2. Jacobson RM, St. Sauver JL, Finney Rutten LJ. Vaccine hesitancy. Mayo Clin Proc 2015:90:1562-8.

3. Larson HJ, Jarrett C, Eckersberger E, et al. Understanding vaccine hesitancy around vaccines and vaccination from a global perspective: a systematic review of published literature, 2007-2012. Vaccine 2014;32:2150-9.

4. Shelby A, Ernst K. How providers and parents can utilize storytelling to combat anti-vaccine misinformation. Hum Vacc Immunother 2013;9:1795-801.

The Editorial Board of Microbiologia Medica Vittorio Sambri, Massimo DePaschale, Roberta Migliavacca, Anna Pierro and Simona Venturoli

Received for publication: 15 June 2016.

Accepted for publication: 15 June 2016.

○C Copyright V. Sambri et al., 2016

Licensee PAGEPress, Italy

Microbiologia Medica 2016; 31:6094

doi:10.4081/mm.2016.6094

This article is distributed under the terms of the Creative Commons Attribution Noncommercial License (by-nc 4.0) which permits any noncommercial use, distribution, and reproduction in any medium, provided the original author(s) and source are credited. 